\title{
Incidental durotomy in the pediatric spine population
}

\author{
James L. West, MD, ${ }^{1}$ Madison Arnel, BA, ${ }^{1}$ Atilio E. Palma, MD, ${ }^{1}$ John Frino, MD, ${ }^{2}$ \\ Alexander K. Powers, MD, ${ }^{1}$ and Daniel E. Couture, MD' \\ Departments of ${ }^{1}$ Neurosurgery and ${ }^{2}$ Orthopedics, Wake Forest Baptist Health, Winston-Salem, North Carolina
}

\begin{abstract}
OBJECTIVE Spine surgery is less common in children than adults. These surgeries, like all others, are subject to complications such as bleeding, infection, and CSF leak. The rate of incidental durotomy in the pediatric population, and its associated complications, has scarcely been reported in the literature.
\end{abstract}

METHODS This is a retrospective chart review of all pediatric patients operated on at Wake Forest Baptist Health from 2012 to 2017 who underwent spine surgeries. The authors excluded any procedures with intended durotomy, such as tethered cord release or spinal cord tumor resection.

RESULTS From 2012 to 2017, 318 pediatric patients underwent surgery for a variety of indications, including adolescent idiopathic scoliosis $(51.9 \%)$, neuromuscular scoliosis $(27.4 \%)$, thoracolumbar fracture $(2.83 \%)$, and other non-fusion-related indications (3.77\%). Of these patients, the average age was 14.1 years, and $71.0 \%$ were female. There were 6 total incidental durotomies, resulting in an overall incidence of $1.9 \%$. The incidence was $18.5 \%$ in revision operations, compared to $0.34 \%$ for index surgeries. Comparison of the revision cohort to the durotomy cohort revealed a trend toward increased length of stay, operative time, and blood loss; however, the trends were not statistically significant. The pedicle probe was implicated in 3 cases and the exact cause was not ascertained in the remaining 3 cases. The 3 durotomies caused by pedicle probe were treated with bone wax; 1 was treated with dry Gelfoam application and 2 were treated with primary repair. Only 1 patient had a persistent leak postoperatively that eventually required wound revision.

CONCLUSIONS Incidental durotomy is an uncommon occurrence in the pediatric spinal surgery population. The majority occurred during placement of pedicle screws, and they were easily treated with bone wax at the time of surgery. Awareness of the incidence, predisposing factors, and treatment options is important in preventing complications and disability.

https://thejns.org/doi/abs/10.3171/2018.5.PEDS17690

KEYWORDS incidental durotomy; pediatric spine surgery; pediatric durotomy; CSF leak

I NCIDENTAL durotomy is a rare but known complication of adult spinal surgery. Estimates vary throughout the literature, but the rate of durotomy can range from $1 \%$ to $18 \%$ depending upon the study cited and the patient characteristics. ${ }^{2,8,9,11-13}$ Although these lesions can be the subject of consternation among clinicians as well as patients, it seems that they do not have a major impact on outcome as long as they are addressed and a persistent CSF leak is not allowed to develop. ${ }^{5}$ Additionally, it is worth noting that uniformly the literature reports high rates of incidental durotomy following revision surgery, likely secondary to scar tissue formation and poor dissection planes. ${ }^{2,4,13}$
Although there is a wide body of literature examining incidental durotomies in the adult spinal surgery population, little has been published regarding these occurrences in the pediatric population. Specifically, few studies have sought to examine the overall incidence of durotomy in the pediatric population and what factors, if any, seem to influence this. ${ }^{4,7}$ This is a rather important research question because the indications for pediatric spinal surgery as well as the anatomical landscape of pediatric spine surgery are quite different than those for the majority of adult cases, which tend to involve degenerative spinal disease such as herniated lumbar disc or lumbar spinal stenosis.

The purpose of this study was to evaluate our experi- 
ence with incidental durotomies among all pediatric spine patients seen at our institution in order to establish an estimate of the rate of incidental durotomy in the pediatric population.

\section{Methods}

This study was a retrospective chart review examining incidental durotomies in pediatric patients (age range 0-18 years) who underwent spinal surgery at Wake Forest Brenner Children's Hospital from 2012 to 2017. Overall, 318 pediatric patients were identified who had undergone spinal surgery, during which a durotomy was not intended as part of the procedure. This excluded cases such as Chiari malformation decompression, tethered cord releases, and spinal cord tumors, among others. In order to ensure no cases were missed, the charts were assessed for occurrence of a durotomy by either coding or mention of "cerebrospinal fluid," "spinal fluid," "durotomy," "dural tear," or "dural rent." These charts were then abstracted in order to determine background demographics, indications for and details of the surgical procedure, the location of tear, the instrument that caused it, and mode of repair. Progress notes were reviewed until discharge in order to assess for any complications associated with the procedure which could be attributable to durotomy.

\section{Results}

\section{Demographic Information and Operative Indications}

The records for 318 patients who underwent spine surgeries at Brenner Children's Hospital were analyzed. The average age of the cohort was 14.1 years and $71.0 \%$ of the patients were female (Table 1). With regard to operative indications, $51.9 \%$ of the operations were for adolescent idiopathic scoliosis and $27.4 \%$ were for neuromuscular scoliosis (Table 1). The remaining operations were indicated for progressive scoliosis not otherwise specified, trauma, and disc herniation.

TABLE 1. Patient demographics and operative characteristics for 318 pediatric patients undergoing spinal surgery

\begin{tabular}{lc}
\hline \multicolumn{1}{c}{ Characteristic } & No. of Patients $(\%)$ \\
\hline Sex & \\
\hline Male & $23(29.0)$ \\
\hline Female & 14.1 \\
\hline Age, yrs & \\
\hline Scoliosis type & $165(51.9)$ \\
\hline Adolescent idiopathic scoliosis & $87(27.4)$ \\
\hline Neuromuscular scoliosis & $34(10.7)$ \\
\hline Progressive scoliosis & $7(2.20)$ \\
\hline Proximal junctional kyphosis & $9(2.83)$ \\
\hline Trauma & $4(1.26)$ \\
\hline Unstable thoracolumbar fracture & $12(3.77)$ \\
\hline Occipitocervical instability & 10.6 \\
\hline Other
\end{tabular}

TABLE 2. Incidental durotomy characteristics

\begin{tabular}{cc}
\hline Characteristic & No. of Patients (\%) \\
\hline Incidence of durotomy & $6(1.9)$ \\
\hline Index op & $1(0.34)$ \\
\hline Revision op & $5(18.5)$ \\
\hline Instrument causing durotomy & $3(50)$ \\
\hline Pedicle probe & $3(50)$ \\
\hline Not specified & \\
\hline Durotomy treatment method & $2(33.3)$ \\
\hline Direct repair & $1(16.7)$ \\
\hline Gelfoam & $3(50.0)$ \\
\hline Bone wax
\end{tabular}

There were 6 total incidental durotomies resulting in an overall incidental durotomy rate of $1.9 \%$ (Table 2). Five of these incidental durotomies occurred during revision procedures. There were 27 revision cases in this series overall, yielding an incidental durotomy rate of $18.5 \%$ for revision cases compared to $0.34 \%$ for index procedures. Because 5 of 6 unintended durotomies occurred during revision procedures, the two groups were analyzed for differences with respect to length of stay (LOS), estimated blood loss (EBL), and operative time (Table 3). Due to a small sample size, none of the observed differences were statistically significant. Of note, 3 durotomy cases (60\%) included pedicle subtraction osteotomy or vertebral column resection, whereas there were 3 such cases within the entire revision cohort (14\%).

Three of the incidental durotomies occurred during placement of pedicle screws when CSF was noted flowing from a pedicle being prepared for screw placement. The pedicle probe was implicated in all 3 of these occurrences. These were treated with the application of bone wax to the pilot hole, and CSF egress was noted to cease. The instrument was not specified in 3 of the cases; however, in 2 of these cases the durotomy occurred during posterior decompression with a combination of Kerrison rongeurs and curettes. The durotomies occurred on the dorsal aspect of the dura, and both were treated with primary suture repair and application of dry Gelfoam.

The sixth incidental durotomy, which was the only nonrevision case, was encountered during reduction and fusion being performed in an 8-month-old child with a traumatic spondyloptosis (Fig. 1). There was no obvious site of egress at the time of surgery, and it was thought that this

TABLE 3. Comparison of revision and incidental durotomy occurring during revision surgery

\begin{tabular}{lcc}
\hline \multirow{2}{*}{ Variable } & \multicolumn{2}{c}{ Median (range) } \\
\cline { 2 - 3 } & Revision Surgery & Revision + Durotomy \\
\hline LOS, days & $4(1-24)$ & $8(2-11)$ \\
\hline EBL, ml & $400(50-1200)$ & $600(100-4000)$ \\
\hline Op time, mins & $206(45-599)$ & $295(225-536)$ \\
\hline Op levels, no. & $11(1-25)$ & $12(6-17)$ \\
\hline
\end{tabular}



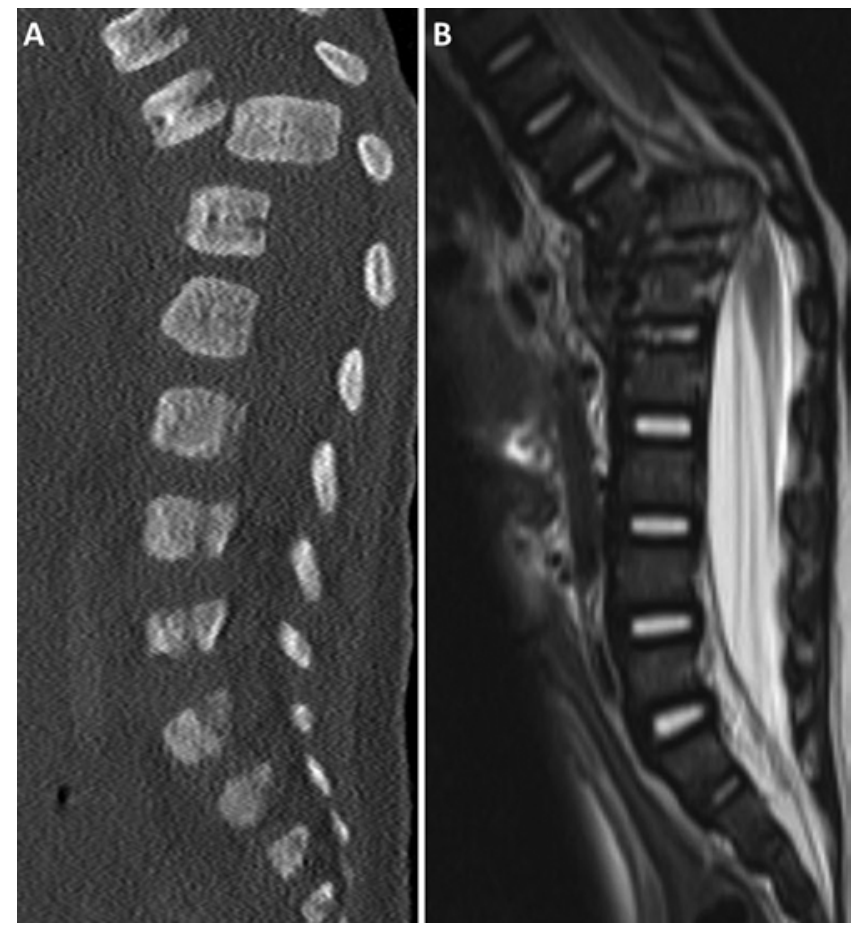

FIG. 1. CT scan (A) and MR image (B) demonstrating traumatic spondyloptosis of T11 on T12 with near-complete effacement of the central canal.

was likely a ventral dural defect secondary to the spondyloptosis itself. A large piece of dry Gelfoam was applied at the time of surgery, and the egress of CSF stopped. This patient went on to develop a CSF leak from the wound and eventually required wound revision for definitive management. Of note, at the time of wound revision, there was still no discrete site of CSF leak identified. This case represented the only occurrence of CSF drainage from the wound or need for further intervention secondary to durotomy (Table 4). All other patients progressed well following occurrence and repair of incidental durotomy, with no long-term sequelae attributable to the durotomy.

\section{Discussion}

Incidental durotomies are a known complication of adult spinal surgery. In our series of 318 pediatric spine surgery patients, the overall rate of incidental durotomy was $1.9 \%$, but it was almost $20 \%$ in revision cases. This study represents the first attempt in the pediatric literature to not only establish a rate of incidental durotomy, but also assess the details surrounding incidental durotomy, such as which instrument caused the durotomy, as well as the effect of durotomy on LOS, operative time, and EBL. Many groups have published their experiences with not only the incidence of these lesions, but also the factors that could predispose patients to the occurrence of an incidental durotomy. ${ }^{2,5,9,12,13}$ In adults, the factors that seem to impact this are older age, severe facet joint pathology, and the presence of a spondylolisthesis. Additionally, our series corroborates previous reports in the adult literature that revision spine surgery carries a higher risk of inci-
TABLE 4. Complications and outcomes

\begin{tabular}{cc}
\hline Parameter & Value \\
\hline Complications, no. ${ }^{*}$ & 1 \\
\hline CSF leak & 1 \\
\hline Wound revision & 0 \\
\hline Meningitis & 0 \\
\hline Neurological deficit & 0 \\
\hline Death & $56 \pm 46.6$ \\
\hline Follow-up, mos
\end{tabular}

* The same patient had both complications listed.

dental durotomy. ${ }^{1,13}$ In spite of numerous reports detailing the incidence, causes, and consequences of incidental durotomy in the adult literature, there has been scant literature concerning the incidence of durotomy in the pediatric population. ${ }^{4}$

When durotomies occur, there are a number of accepted ways to repair them, from direct repair with suture, to the overlay of newer compounds designed to seal off the dural rent. ${ }^{6,712}$ Ultimately, the optimum method for repair depends primarily on not only the anatomical location of the durotomy, but also the mechanism by which it occurred. In the adult literature, durotomies typically occur during decompression of the thecal sac..$^{12}$ In our series, the pedicle probe was implicated in half of the identified durotomies. If the breach is medial or inferior, this could produce a durotomy by injuring the dura of the thecal sac itself or the exiting nerve root. Given the clinically silent nature of these durotomies, they are likely caused by sharp cortical bone from a small pedicle fracture rather than the probe itself. Alternatively, CSF leaks associated with pedicle screw placement can be secondary to the sharp edges of the bone tap lacerating the dura during preparation for screw placement. When these probe-related durotomies occurred, they were treated with generous application of bone wax into the pilot hole. We believe this creates a resistance to flow that prevents further egress of CSF down the pilot hole and that, because these occur at the nerve root shoulder, they are in close apposition to bone and epidural fat, which provides further resistance to CSF flow dorsally, effectively creating a small, contained pseudomeningocele at the nerve root shoulder, which will eventually regress. ${ }^{3,10}$

Indications for pediatric spine surgery vary greatly from those for adults, with instrumented fusion for scoliosis being the most common indication for pediatric spinal surgery in our cohort. The different indications for surgery likely explain why we found the pedicle probe to be implicated in half of durotomies, whereas in the adult literature, the durotomy typically occurs during decompression. In the present series, a number of methods were employed depending on location of the durotomy, and all seemed to prevent CSF leakage or the need for further revision surgeries. The gold standard remains primary repair with suture when possible. In many cases, this is not possible when the durotomy occurs in an inaccessible region, such as during pedicle screw placement. Bone wax or Gelfoam occlusion of the site seems a viable alternative to direct repair. 
Although the overall incidence of durotomy in this study resulted in too few cases of durotomy to assess for prognostic factors by regression analysis, a number of comparisons were possible between the revision cohort and the durotomy cohort. Specifically, although not statistically significant, there were trends for increased LOS and operative time. Additionally, inclusion of a significant osteotomy, such as vertebral column resection or pedicle subtraction osteotomy, appears to increase the risk of durotomy, although statistical significance could not be established due to the small sample size. These variables, as identified by this study, should be included in future studies assessing risk factors for pediatric unintended durotomy.

There are several limitations to this study as it was conducted. First, it represents a retrospective chart review of a single center's experience with pediatric spinal surgery and is prone to resultant biases. Specifically, retrospective studies tend to underreport complications as they rely on documentation to confirm occurrence of the event. Additionally, there was no prospective imaging after the event to assess for issues such as pseudomeningocele formation, although there is no clear consensus regarding the management of clinically asymptomatic pseudomeningocele..$^{3,10}$ Additionally, a single-institution study could introduce local practice-pattern biases, and as such, a multiinstitutional study is needed to confirm and further expound upon the results of this study. Ideally, a multicenter prospective study or database detailing not only the incidence of durotomy in the pediatric spine population but also the consequences and potential predictors of incidental durotomy is needed in the future.

\section{Conclusions}

Overall, the rate of incidental durotomy is lower in children than adults, which could be predicted based on more favorable anatomy with less degenerative distortion or stenosis compared to adults. Incidental durotomy was more likely to occur during placement of instrumentation in children than adults, likely reflective of the different indications for pediatric and adult spinal surgery. Like their adult counterparts, children appear to tolerate incidental durotomies well when the lesions are addressed at the time of surgery, and they rarely go on to become CSF leaks or require wound revision. The impact of incidental durotomy on LOS, operative time, and EBL should be investigated further in future studies. Although prevention is key, in an era of increasing emphasis on quality, it is important to establish honest, real-world baselines for expected complications such as incidental durotomy and their potential impact on quality metrics.

\section{References}

1. Bosacco SJ, Gardner MJ, Guille JT: Evaluation and treatment of dural tears in lumbar spine surgery: a review. Clin Orthop Relat Res (389):238-247, 2001
2. Cammisa FP Jr, Girardi FP, Sangani PK, Parvataneni HK, Cadag S, Sandhu HS: Incidental durotomy in spine surgery. Spine (Phila Pa 1976) 25:2663-2667, 2000

3. Couture D, Branch CL Jr: Spinal pseudomeningoceles and cerebrospinal fluid fistulas. Neurosurg Focus 15(6):E6, 2003

4. De la Garza Ramos R, Goodwin CR, Purvis T, Karikari IO, Samdani AF, Sciubba DM: Primary versus revision spinal fusion in children: an analysis of 74,525 cases from the Nationwide Inpatient Sample. Spine (Phila Pa 1976) 42:E660E665, 2017

5. Desai A, Ball PA, Bekelis K, Lurie J, Mirza SK, Tosteson TD, et al: SPORT: does incidental durotomy affect longterm outcomes in cases of spinal stenosis? Neurosurgery $\mathbf{7 6}$ (Suppl 1):S57-S63, 2015

6. Eismont FJ, Wiesel SW, Rothman RH: Treatment of dural tears associated with spinal surgery. J Bone Joint Surg Am 63:1132-1136, 1981

7. Goodwin CR, Recinos PF, Zhou X, Yang JX, Jallo GI: Evaluation of complication rates of pediatric spinal procedures in which a polyethylene glycol sealant was used. J Neurosurg Pediatr 13:315-318, 2014

8. Guerin P, El Fegoun AB, Obeid I, Gille O, Lelong L, Luc S, et al: Incidental durotomy during spine surgery: incidence, management and complications. A retrospective review. Injury 43:397-401, 2012

9. Jones AA, Stambough JL, Balderston RA, Rothman RH, Booth RE Jr: Long-term results of lumbar spine surgery complicated by unintended incidental durotomy. Spine (Phila Pa 1976) 14:443-446, 1989

10. Solomon P, Sekharappa V, Krishnan V, David KS: Spontaneous resolution of postoperative lumbar pseudomeningoceles: a report of four cases. Indian J Orthop 47:417-421, 2013

11. Stolke D, Sollmann WP, Seifert V: Intra- and postoperative complications in lumbar disc surgery. Spine (Phila Pa 1976) 14:56-59, 1989

12. Takahashi Y, Sato T, Hyodo H, Kawamata T, Takahashi E, Miyatake N, et al: Incidental durotomy during lumbar spine surgery: risk factors and anatomic locations: clinical article. J Neurosurg Spine 18:165-169, 2013

13. Wiesel SW: The multiply operated lumbar spine. Instr Course Lect 34:68-77, 1985

\section{Disclosures}

The authors report no conflict of interest concerning the materials or methods used in this study or the findings specified in this paper.

\section{Author Contributions}

Conception and design: West, Frino, Powers, Couture. Acquisition of data: West, Arnel. Analysis and interpretation of data: West, Arnel. Drafting the article: West, Arnel, Palma, Couture. Critically revising the article: Palma, Frino, Powers, Couture. Reviewed submitted version of manuscript: West, Couture. Approved the final version of the manuscript on behalf of all authors: West. Administrative/technical/material support: Frino, Powers, Couture. Study supervision: Frino, Powers, Couture.

\section{Correspondence}

James West: Wake Forest Baptist Health, Winston-Salem, NC. jlwest@wakehealth.edu. 